\title{
Technical note: The use of a sonomicrometry system for monitoring uterine involution in postpartum dairy cows
}

\author{
M. Heppelmann, ${ }^{* 1}$ K. Krach,, L. Krüger, ${ }^{*}$ P. Benz, ${ }^{*}$ K. Herzog, ${ }^{*}$ M. Piechotta, ${ }^{*}$ M. Hoedemaker, ${ }^{*}$ \\ and $\mathrm{H}$. Bollweint \\ ${ }^{*}$ Clinic for Cattle, University of Veterinary Medicine Hannover, Foundation, Bischofsholer Damm 15, 30173 Hannover, Germany \\ †Clinic of Reproductive Medicine, Vetsuisse Faculty, University of Zurich, Winterthurerstrasse 260, CH-8057 Zurich, Switzerland
}

\begin{abstract}
Sonomicrometry allows the measurement of the distance between 2 piezoelectric crystals and has been widely used to investigate the contractility of the heart and gastrointestinal tract. The objective of this study was to determine whether this method can be used to quantify the reduction in uterine size in cows postpartum. Seven healthy pluriparous Holstein Friesian cows $(3.7 \pm 0.7$ yr old, parity $2.4 \pm 0.5$, mean $\pm \mathrm{SD})$ were used. Three weeks before calving, 4 piezoelectric crystals were implanted via laparotomy in the myometrium of the greater curvature of the pregnant uterine horn in a longitudinal direction. Sonometric measurements were conducted daily from $2 \mathrm{~d}$ before parturition until 14 $\mathrm{d}$ after calving, followed by measurements every other day until $\mathrm{d} 28$. Changes in the distance between neighboring crystals were presented as relative changes (\%) from baseline values before parturition. The diameter of the previously pregnant uterine horn was measured using transrectal B-mode sonography from d 10 to 28 after calving. The cows were slaughtered $39 \pm 6$ d postpartum and the uterus was evaluated for fixation of the crystals. The distances between neighboring crystals underwent changes with a reduction of greater than $50 \%$ until d 1 postpartum, but no further changes were recorded from d 1 to 7 . In the second week, changes in all distances were affected by day postpartum. One distance was affected by day postpartum in wk 3 and 4. There was a positive correlation between the diameter of the previously pregnant horn and the distances between the crystals. Examination of the uterus after slaughter of the cows revealed that 8 crystals (29\%) were no longer fixed in the myometrium. Seven of these (25\%) could be evaluated completely or partially and 1 (4\%) could not be analyzed. Sonomicrometry seems to be suitable for the objective measurement of reduction in uterine length in cows.
\end{abstract}

Received September 13, 2013.

Accepted November 10, 2014.

${ }^{1}$ Corresponding author: Maike.Heppelmann@tiho-hannover.de
Key words: postpartum period, uterus, cattle, sonography

\section{Technical Note}

Uterine involution after parturition is a critical part of the reproductive process of the cow. It is characterized by the return of the uterus to its previous size, endometrial regeneration, resumption of ovarian cyclicity, and elimination of bacterial contamination (Sheldon and Dobson, 2004; Frazer, 2005). Disruption of any of these events may affect fertility (Fonseca et al., 1983). Postpartum diseases of the genital tract, such as retained fetal membranes and metritis, and metabolic disorders (ketosis and hypocalcemia), have a negative effect on uterine involution (Fourichon et al., 2000; Ribeiro et al., 2013). Close monitoring of uterine involution is important from a clinical perspective and is also used as a research tool. Assessment of uterine size is particularly relevant in the first few days postpartum, during which time the major part of the involution occurs as evidenced by massive muscle contractions and evacuation of lochia (Gier and Marion, 1968; Zerobin, 1970; Frazer, 2005).

Various methods have been used for the assessment of uterine involution in cows, including transrectal palpation (Morrow et al., 1969; Watson, 1985) and transrectal B-mode sonography (Okano and Tomizuka, 1987; Kamimura et al., 1993; Bekana et al., 1994; Melendez et al., 2004). These techniques are noninvasive and relatively simple and primarily serve to assess uterine size and tone. The main disadvantage of these techniques is that they cannot be used to assess the entire uterus during the first days after calving (Kamimura et al., 1993). Furthermore, the results of these techniques have limited accuracy, and assessment by transrectal palpation is subjective (Okano and Tomizuka, 1987; Bekana et al., 1994). Uterine involution can also be assessed indirectly by measurement of blood flow in the uterine artery using Doppler sonography (Krueger et al., 2009; Heppelmann et al., 2013) or by measurement of intrauterine pressure transcervically (RodriguezMartinez et al., 1987; Hirsbrunner et al., 1999; Bajcsy 
et al., 2005) or invasively using microtransducers and tip catheters implanted via laparotomy (Gillette and Holm, 1963; Kündig et al., 1990). Other invasive measuring techniques include electromyography (Kündig et al., 1990; Gajewski et al., 1999; Taverne et al., 2002) and the recording of uterine contractions and stretching using strain gauge transducers (Burton et al., 1987). A commonality of these methods is that they are useful for recording uterine contractions, but they do not measure reduction in uterine size during involution.

Sonomicrometry allows the objective estimation of the distance between individual piezoelectric crystals based on the measurement of the time required for an ultrasound signal to travel between them. Crystals affixed to the tissue of the organ to be examined can transmit or receive ultrasound bursts (Adelson and Million, 2004), and the distance between transmitter and receiver can be calculated based on a constant signal transit speed of $1.59 \mathrm{~mm} / \mu \mathrm{s}$ determined for mammalian soft tissue. Sonomicrometry has been widely used in experimental cardiovascular studies (Korinek et al., 2007), for the investigation of gastrointestinal motility in small animals (Adelson and Million, 2004; Ouyang and Chen, 2005), and for the measurement of changes in muscle length in pigeons and toads (Biewener et al., 1998; Ahn et al., 2003). These studies have shown that changes in the size of an organ can be monitored directly and continuously using sonomicrometry, but differentiation between active and passive movement of an organ is not possible (Adelson and Million, 2004). To date, the use of sonomicrometry in cattle has been limited to the measurement of cervical diameter in the periparturient period (Breeveld-Dwarkasin et al., 2002; van Engelen et al., 2007).

There are no techniques available for the objective assessment in reduction of uterine size during the early puerperal period. Therefore, the current study was carried out to investigate the feasibility of sonomicrometry for this purpose. Our objective was to establish an experimental technique for the assessment of the effects of postpartum disease on reduction of uterine size and whether these effects can be modified by therapeutic measures.

\section{Sonomicrometry System}

The sonomicrometry system (Sonometrics Corp., London, Canada) used consisted of 4 piezoelectric crystals, the sonomicrometer (TRX8), the ChannelSelector-Box, and a Sonometrics Data Acquisition Computer. The epoxy-coated crystals were $4 \mathrm{~mm}$ in diameter and mounted on a rigid neck part, which was about $15 \mathrm{~mm}$ in length and connected to the skin button via a 2-m length of silicone-coated cable (Figure
1). The sonomicrometer generated ultrasound signals in the piezoelectric crystals and converted the received analog signals into digital signals. The length of the transmission pulses was $400 \mathrm{~ns}$ and the frequency was $25 \mathrm{~Hz}$. The crystals that served as transmitter and receiver were chosen by means of the Channel-SelectorBox. The selected distance between the transmitting and receiving crystals was monitored on an oscilloscope (54600B $100 \mathrm{MHz}$, Hewlett Packard, Palo Alto, CA) to check the signal quality. To identify artifacts caused by movements of the cows, video recordings were made of the animals during measurements and recorded and stored on a personal computer.

\section{Animals}

Seven healthy pluriparous Holstein Friesian cows housed at the Clinic for Cattle of the University of Veterinary Medicine Hannover, Foundation, were examined from 3 wk before to 4 wk after calving. The cows were $3.7 \pm 0.7 \mathrm{yr}$ (mean $\pm \mathrm{SD}$ ) of age and weighed $686 \pm 63 \mathrm{~kg}$. Parity was $2.4 \pm 0.5$, BCS was $3.8 \pm 0.4$, and the $305-\mathrm{d}$ FCM yield was $7,779 \pm 941 \mathrm{~kg}$. The cows were kept in isolated boxes with straw bedding and fed hay and corn silage ad libitum. Before calving the cows received $1 \mathrm{~kg}$ of concentrate $(18 \%$ CP, St.Mv.18 III Pell.; ForFarmers Bela GmbH, Vechta, Germany) twice daily; after calving concentrate was fed according to milk yield. After calving cows were milked twice daily. General clinical examinations were conducted each day

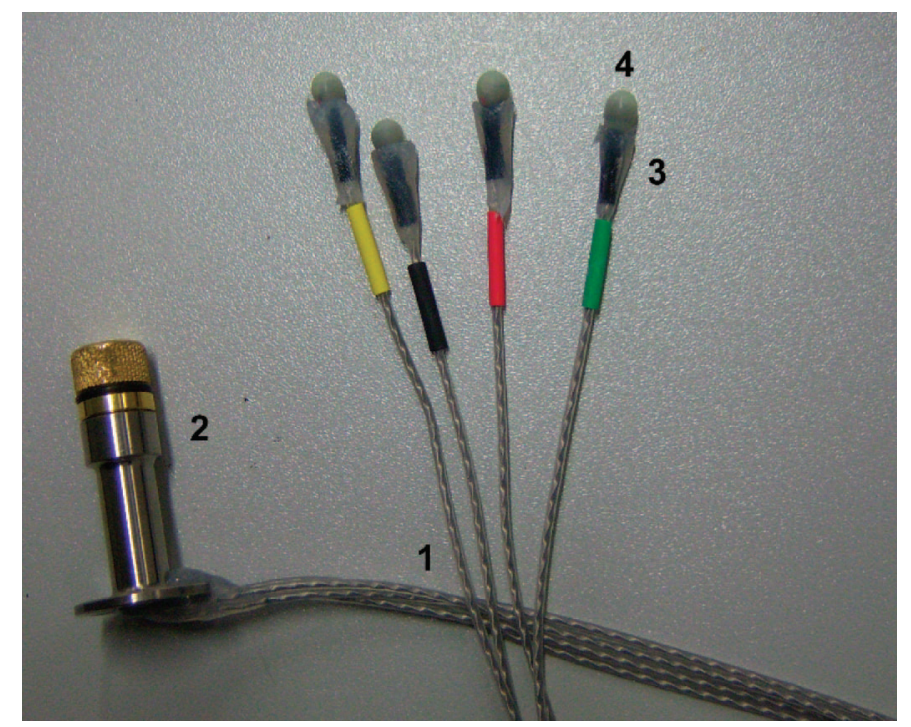

Figure 1. Four piezoelectric crystals (Sonometrics Corp., London, ON, Canada) with silicone-coated cables (1) connected to the skin button (2). A silicone collar (3) was applied to the neck part below the head of the crystals (4) for better fixation of the sutures. Color version available online. 
during the study period. The study was approved and conducted in accordance with German legislation on animal rights and welfare (33.9-42502-04-09/1696).

\section{Surgery}

The crystals of the sonomicrometry system were surgically implanted into the uterine wall 3 wk before the calculated calving date. The cows were fasted for 2 $\mathrm{d}$ before surgery to reduce rumen fill. The sonometric crystals were fitted with a silicone collar $(2 \mathrm{~cm}$ long, 3 $\mathrm{mm}$ thick) at the neck part to facilitate fixation with sutures (Figure 1). Immediately before surgery, the crystals and cables were disinfected for $1 \mathrm{hr}$ using $2 \%$ chlorine-cresol-chlorine-benzyl phenol solution and 1\% povidone iodine, respectively. The skin of the left flank of the cow was clipped and prepared surgically. A distal paravertebral block combined with infiltration of the incision site with $250 \mathrm{~mL}$ of $2 \%$ procaine hydrochloride with epinephrine was used for anesthesia. A 30-cm incision was made in the middle of the left flank in a dorsoventral direction, and a trocar with a stylet and a diameter of $13 \mathrm{~mm}$ was passed through the abdominal wall from the peritoneum to the skin approximately 3 $\mathrm{cm}$ caudodorsal to the dorsal edge of the incision. The stylet was removed and the crystals were introduced into the abdomen through the trocar, which was then withdrawn. The greater curvature of the pregnant uterine horn was lifted into the incision by an assistant, and the 4 crystals were fixed in a sagittal plane along the greater curvature of the pregnant horn. The most caudal crystal (number 4) was placed near the bifurcation of the uterus and the other 3 (numbers 3,2 , and 1 ) were placed cranially at intervals of approximately 10 $\mathrm{cm}$. For fixation of the crystals, an incision was made through the serosa and outermost muscle layer of the uterus. A loop was made in the cable to prevent accidental dislodgement of the crystal, and the crystal head was buried using number 2 (metric size) silk in a single seromuscular cruciate suture pattern. A second similar suture was used to fix the silicone collar. The loop of the cable was attached to the uterus with 3 single sutures (Figure 2). Approximately three-fourths $(150 \mathrm{~cm})$ of the length of the cable was allowed to remain loose in the abdomen in an attempt to prevent traction on the crystals. The abdominal wall including the skin was sutured. The skin was incised between the point where the cables exited and the tip of the transverse spinous process dorsally and the cables placed subcutaneously. The skin was closed using a number 6 (metric size) coated multifilament nylon suture in a continuous suture pattern. Finally, the skin button was fixed to the skin with single sutures. Starting on the day of surgery, the cows received enrofloxacin $(2.5 \mathrm{mg} / \mathrm{kg}$ of BW s.c.;

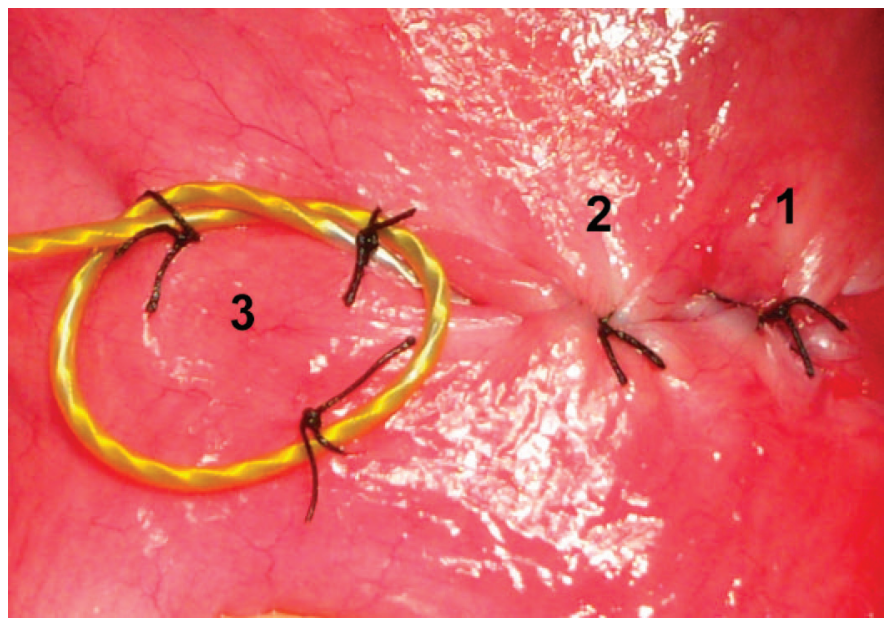

Figure 2. Fixation of a crystal at the greater curvature of the gravid uterine horn: Position of the crystal head (1) and the silicone collar (2) under the serosa and outer muscle layer of the uterus. The crystals and silicone collars were fixed with a nonperforating seromuscular cruciate suture. The loop in the cable was attached to the uterus with 3 single sutures (3). Color version available online.

WDT, Garbsen, Germany) for $5 \mathrm{~d}$, benzylpenicillin (20,000 IU/kg of BW s.c.; Albrecht GmbH, Aulendorf, Germany) for another $5 \mathrm{~d}$, and flunixin meglumine $(2.2 \mathrm{mg} / \mathrm{kg}$ of BW s.c.; cp-pharma Handelsgesellschaft $\mathrm{mbH}$, Burgdorf, Germany) for $3 \mathrm{~d}$ after surgery.

Sonometric measurements were carried out weekly from $3 \mathrm{wk}$ to $2 \mathrm{~d}$ before the calculated calving date to test the function of the crystals. After calving, measurements were made during a 4-h period from 0900 to 1300 $\mathrm{h}$ daily until d 14 postpartum followed by every other day until d 28. During calving, continuous recordings were made from the time the cervix started to dilate until the time the fetal membranes were passed, or $12 \mathrm{~h}$ postpartum if the placenta was retained. In addition to the video recording, physical activities of the cows were recorded in a written log. The signal quality of each distance between neighboring crystals was monitored continuously with the oscilloscope during recordings to correct the minimal time difference between transmission and reception of the signal and the sensitivity of the crystals accordingly.

\section{Sonometric Measurements and Analysis}

SonoSOFT software (version 3.4.30 RC1, Sonometrics Corp.) was used for data acquisition and analysis. Only the data from adjacent crystals were used. From each possible crystal transmission pair (e.g., 1 to 2 and 2 to 1 ), the direction with the better signal quality was selected. This resulted in 3 distances between crystals that remained for final analysis and these measurements were presented graphically using 
the software SonoVIEW (Sonometrics Corp.). The distances were filtered with a SonoSOFT Filter, during which single point outliers were assigned to the actual distance between crystals. Recorded distances that appeared abnormal were compared with video recordings and written logs from the exact same time, and those changes in distances between crystals that could be directly correlated with specific cow movements (rising, lying down, defecation, urination) were eliminated from analysis. Furthermore, periods with poor signal quality, which was defined as sets of signal sets with more than $10 \%$ erroneous values, were excluded from analysis; erroneous values were defined as recorded distances with a deviation from the actual distance between 2 crystals of more than 1 SD. When more than $75 \%$ of the data were excluded from analysis, the entire data set was rejected.

Sudden deviation of all 3 distances measured by a crystal from previously measured distances in the absence of corresponding cow movements was interpreted as detachment of that crystal. The sudden changes in recorded distances were caused by folding of the detached crystal into another position. Detached crystals were classified according to the quality of the sonometric data. All distances recorded by detached crystals in a folded position were excluded from analysis. Crystals were classified as completely analyzable when more than $75 \%$ of the data were available, as partly analyzable when 25 to $75 \%$ of the data were available, and as not analyzable when $<25 \%$ of the data were available.

For each cow, the distance between 2 neighboring crystals with the fewest erroneous values was chosen and presented graphically. Frequency and duration of contractions were evaluated. Two types of uterine contractions were identified; short contractions had a duration of 0.5 to $1.5 \mathrm{~min}$ and long contractions lasted 3 to $10 \mathrm{~min}$. The 2 types of contractions mostly occurred simultaneously.

\section{Ultrasonography and Postmortem Examination}

Transrectal B-mode sonographic examination of the previously gravid uterine horn was conducted for comparison with the sonometric measurements. Beginning on d 10 after calving, a cross-sectional image of the uterine horn approximately $2 \mathrm{~cm}$ cranial to the bifurcation was obtained after each sonometric measurement. The diameter $(\mathrm{cm})$ was calculated as the mean of the maximum height and width of the endometrium. For validation of the effect of surgery and implanted crystals on reduction in uterine size, the same sonographic examinations were conducted in 7 cows from the Research Farm of the University of Veterinary Medicine Hannover (control group). To facilitate the comparison between the 2 groups, cows with the same parity as the experimental cows were selected as controls, 2 of which had retained fetal membranes.

The cows were slaughtered an average of $39 \pm 6 \mathrm{~d}$ postpartum and the uteri were examined for fixation of the crystals. Each crystal was classified as fixed (entire crystal including silicone collar located in the myometrium), partly fixed (head of crystal loose), and not fixed (head and collar of the crystal were loose).

\section{Statistical Analysis}

Statistical analyses were carried out using SAS software (version 9.2; SAS Institute, Cary, NC). The Shapiro-Wilk test showed that most distributions of the residuals of the sonometrically determined distances were not normal, and median values for every day after calving were therefore calculated. The median of the day was calculated from the medians of the 4 data sets of $1 \mathrm{~h}$. The median distance between neighboring crystals recorded on $1 \mathrm{~d}$ between $\mathrm{d} 8$ and 3 prepartum (5.4 $\pm 1.8 \mathrm{~d})$ was chosen as reference value $(100 \%)$ for the calculation of relative changes postpartum. Selection of a uniform reference day before parturition was not possible because the actual calving date deviated from the calculated. The relative changes and frequency of contraction had normal distributions and are given as mean \pm SD. The effects of day postpartum, uterine location of the distances on relative changes, and occurrence of retained fetal membranes were determined for each week separately and the effect of day postpartum on frequency of contraction was analyzed for the whole investigation period as repeated measurements using PROC MIXED. Time (day postpartum), location (uterine location of the distance), and occurrence of retained fetal membranes were defined as fixed effects; cow was specified as a random term. The BayesianSchwarz criterion and Akaike information criterion were used to determine the optimal covariance structure matrix (relative changes and short contractions: variance components; long contractions: toeplitz) to use in the repeated statement (Littell et al., 2000). Differences among distances between neighboring crystals were analyzed on a weekly basis using the Scheffe test (PROC GLM). The relationship between the intercrystal distances and the diameter of the previously gravid uterine horn was examined using Spearman correlation coefficients ( $r$; PROC CORR); coefficients from 0 to $0.25,0.26$ to $0.50,0.51$ to 0.75 , and $>0.75$ indicated poor, moderate, good, and very good correlations, respectively (Dawson and Trapp, 2004). Differences in diameter of the previously gravid uterine horn between experimental and control cows were analyzed using a one-way ANOVA (PROC GLM). Effect of uterine 


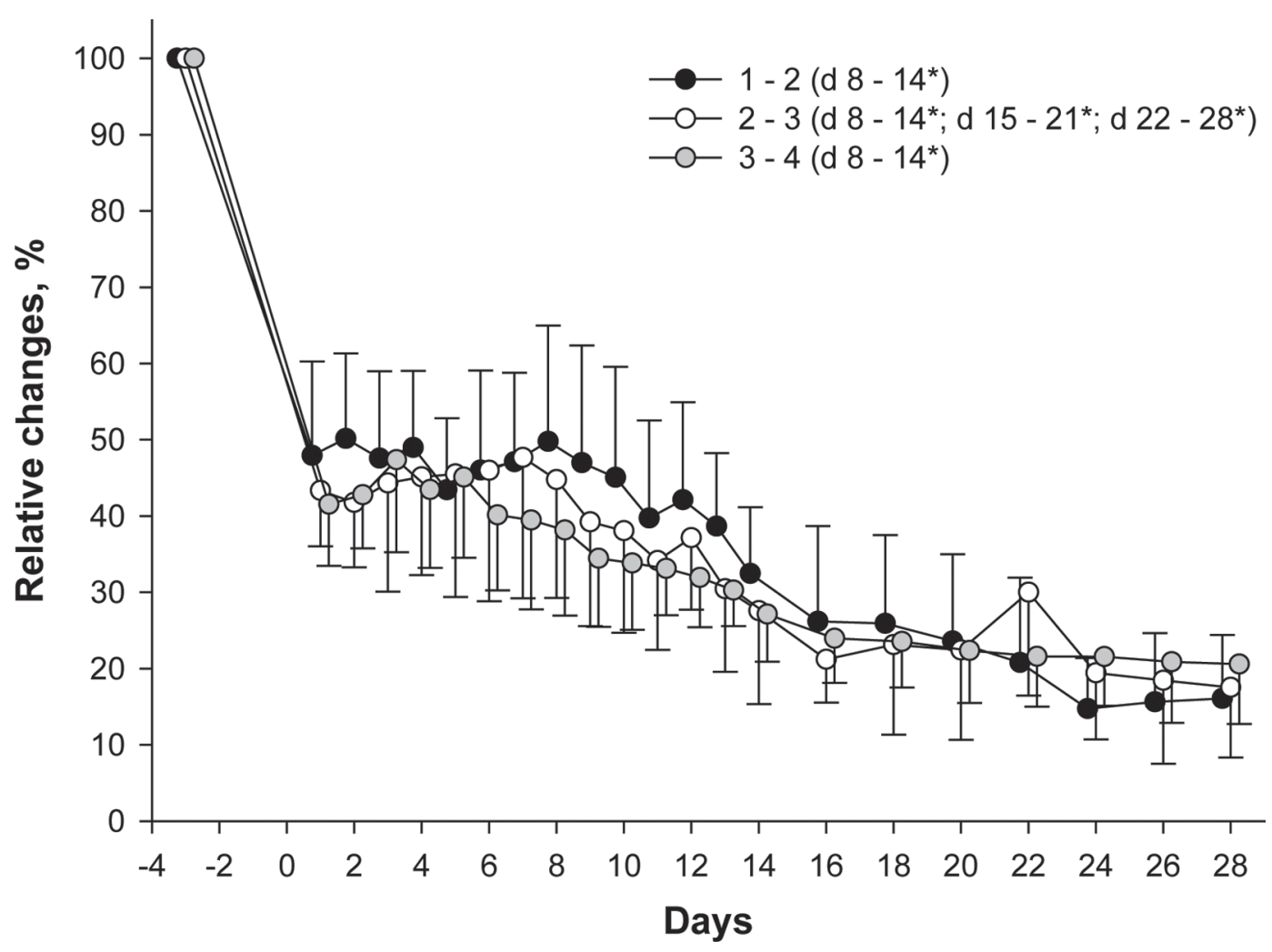

Figure 3. Relative changes (means $\pm \mathrm{SD}$ ) of the sonometrically determined distances between piezoelectric crystals $(1,2,3$, and 4$)$ implanted into the uterine wall of 7 cows during the first $28 \mathrm{~d}$ postpartum. Changes were relative to baseline values taken 3 to $8 \mathrm{~d}$ before calving $(\mathrm{d} 0=$ day of calving). For the indicated time periods, an effect of day postpartum on distance was observed $\left({ }^{*} P<0.01\right)$.

location on fixation was evaluated using the $\chi^{2}$ test of homogeneity (PROC FREQ). Values of $P<0.05$ were considered significant.

\section{Results}

All cows had normal wound healing. The mean gestation length was $279.3 \pm 2.7 \mathrm{~d}$. Birth was assisted by light manual traction in 5 of the 7 cows. Six calves were born alive and 1 was stillborn, and the birth weight was $47.5 \pm 5.0 \mathrm{~kg}$. Two cows had retained fetal membranes. Because of technical problems with the personal computer, all distance data for 3 of the days were lost. Of the remaining data, $5 \%$ could not be analyzed because of cow movement or poor signal quality.

In all cows, all 3 distances decreased by more than $50 \%$ between antepartum and d 1 postpartum $(P<$ 0.0001; Figure 3). Day postpartum had an effect on all distances in wk 2 after calving and on the distance between crystals 2 and 3 in wk 3 and 4 postpartum $(P$ $<0.05$ ). An effect of uterine location on distance was observed in wk 2 when the distance between crystals 1 and 2 was greater than the distance between crystals 3 and $4(P<0.0001)$. No effects of day and uterine location were noted in the remaining weeks $(P>0.05)$.
Occurrence of retained fetal membranes had no effect on relative changes in distances $(P>0.05)$.

Short contractions could not be analyzed in 24 daily recordings $(16 \%)$ because of poor signal quality. Eighteen $(75 \%)$ of the 24 recordings were made in wk 1 postpartum. Long contractions could be analyzed throughout the study period. Frequency of long contractions, but not frequency of short contractions, was affected by day postpartum $(P<0.01$; Figure 4$)$.

The correlations between the diameter of the previously pregnant uterine horn measured by transrectal B-mode sonography and distances 1 to 2,2 to 3 , and 3 to 4 were moderate to good $(r=0.54, r=0.43$, and $r=0.63$, all $P<0.01$, respectively). No difference in diameter of the previously pregnant uterine horn was observed between experimental and control cows $(P>$ $0.05)$.

Postmortem examination of the uteri revealed that $20(71 \%)$ of the crystals were fixed, $3(11 \%)$ were partly fixed, and $5(18 \%)$ were not fixed in the myometrium. All loops formed by the cables were largely or completely adhered to the uterine surface through fibrinous adhesions. Of the partly fixed and nonfixed crystals, 3 cows had 1 affected crystal, 2 cows had 2 affected crystals, and 2 others had 3 affected crystals. Uterine 


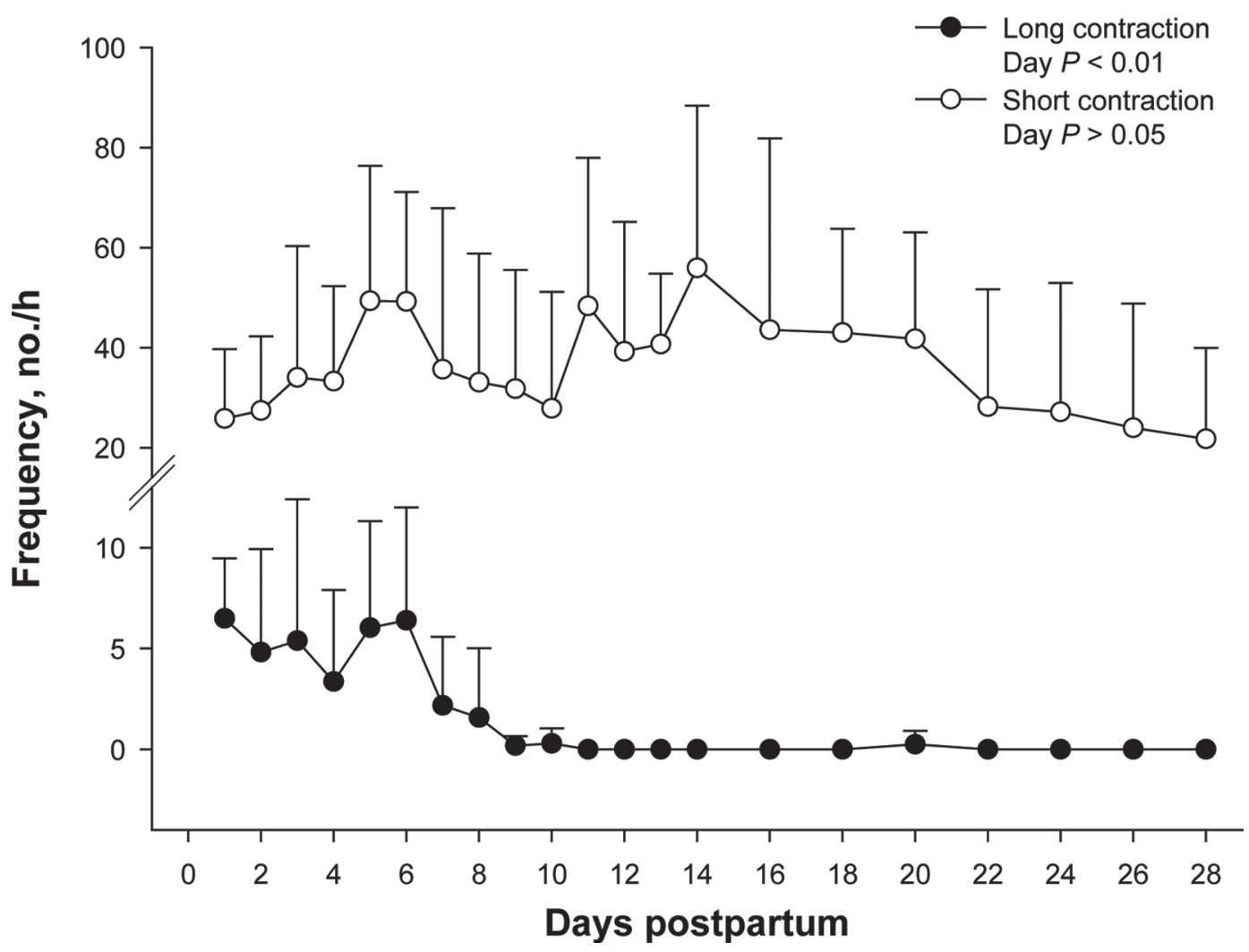

Figure 4. Frequency of short (0.5 to $1.5 \mathrm{~min}$ ) and long uterine contractions (3 to $10 \mathrm{~min}$ ) in 7 cows during the first $28 \mathrm{~d}$ postpartum (means $\pm \mathrm{SD})$.

location did not affect fixation $(P>0.05)$. None of the fixed crystals were classified as detached during measurement. One nonfixed crystal (4\%) was classified as not detached during measurement. Six partly fixed or nonfixed crystals (21\%) could be evaluated completely or partially. Recordings from 1 partly fixed crystal (4\%) could not be analyzed.

\section{Discussion}

The sonometric system used in our study measured distances between crystals sonographically and can therefore be considered an objective method for the assessment of the reduction in uterine size. We attempted to implant the 4 crystals into the uterine wall at equal distances. However, because of varying contractility of different sections of the uterus during surgery and changes in uterine size between implantation and calving, the distances between crystals were not entirely equidistant within and between cows, and therefore not directly comparable among cows. Relative changes in the distances between neighboring crystals were therefore used to characterize uterine involution based on baseline measurements obtained before calv- ing. According to previous studies (Gier and Marion, 1968; Van Camp, 1991), the length of the previously gravid uterine horn decreased the most during the first day postpartum, when the muscle fibers were reduced in length from 750 to 400 microns (Gier and Marion, 1968; Van Camp, 1991). A further marked decrease in uterine size was reported by others during the next few days (Gier and Marion, 1968; Morrow et al., 1969; Van Camp, 1991), but in our study the uterine length did not change significantly during the remaining days of the first week postpartum. A further significant reduction in the intercrystal distances occurred in the second week. Various uterine size variables are used to monitor involution, and they have different profiles over time; this could account, at least in part, for discrepancies between our results and other studies. For instance, the length of the previously pregnant horn decreases much more slowly than uterine weight or diameter; uterine weight and diameter decreased by 62 and $57 \%$, respectively, between d 1 and 8 postpartum, whereas uterine length decreased by only $40 \%$ during the same period (Gier and Marion, 1968). Our results are in agreement with findings of Morrow et al. (1966), who used transrectal palpation to monitor involution and observed 
a slow decrease in uterine size between d 4 and 9 and a marked decrease between d 10 and 14 postpartum. However, it should be noted that assessment of uterine involution by transrectal palpation is subjective and prone to error (Okano and Tomizuka, 1987; Bekana et al., 1994). During the second week after calving, the cranial-most intercrystal distance (between crystals 1 and 2) underwent a slower reduction than the caudal distance, indicating that caudal parts of the uterus undergo more rapid reduction in length than cranial parts. Occurrence of retained fetal membranes had no influence on reduction of uterine size. Given that only 2 cows were included in the statistical model, this result should be interpreted with caution.

The observation of weak individual contractions as well as stronger and longer contraction waves during the first few days postpartum in the present study was in agreement with an earlier report (Kündig et al., 1990). However, evaluation of the short contractions was more difficult than that of the long contractions, especially in the very early postpartum period. A possible reason for this is the common occurrence of erroneous measurements during the first few days postpartum, possibly related to the relatively large distances between crystals. The occurrence of short contractions was not affected by time, whereas the long contractions only occurred during the first $8 \mathrm{~d}$ postpartum. The pattern of long contractions corresponded with that described in other studies (Kündig et al., 1990; Gajewski et al., 1999) in which uterine contractions decreased markedly within the first few days postpartum after the release of the fetal membranes. This decrease was explained by a reduction in blood estrogen concentration during this period (Kündig et al., 1990).

A critical part of the experiment was the validation of the sonometric measurements. Because no objective in vivo reference method exists for the assessment of the reduction in uterine length, we used transrectal Bmode sonographic measurements of the cross-section of the uterine horn for validation of the sonometric data. Comparison of sonomicrometry and sonography yielded moderate to good correlations. A comparison was not possible during the first few days postpartum because the uterus was not amenable to transrectal sonography because of its large size (Krueger et al., 2009). A stronger correlation between findings of the 2 techniques could not be expected because sonomicrometry measured the reduction in uterine length and sonography the reduction in uterine diameter, each with different profiles over time (Gier and Marion, 1968), as mentioned previously.

Implantation and fixation of the crystals in the myometrium was a critical step in our experiment. Delivery of the calf and uterine involution are characterized by rapid and enormous reduction in uterine size, which places the fixation of the crystals under great tension. As a result, 8 of the 28 crystals were not fixed adequately in the myometrium at the end of the study. Direct traction on the cables is not likely to have caused detachment of the crystals because all loops were still attached to the uterus. Rather, it appears that the crystal heads and the rigid neck parts were expelled from their locations, and therefore became exposed, during the massive shrinkage of the uterine tissue. With one exception, the detached crystals could be identified on the basis of the recordings they generated. Detachment of the crystals was recognized by a sudden change in the distances recorded by the crystal in the absence of an obvious reason. Fortunately, the data of almost all crystals could be used in their entirety or at least partly for further analysis, albeit under exclusion of erroneous measurements from the data sets.

Because it was conceivable that surgical implantation of the crystal itself would have an effect on uterine involution, the surgery was carried out 3 wk before the expected calving date. Wound healing was normal in all cows and therefore external fixation of the cables did not seem to affect the well-being of the cows. To validate the effect of surgery and implanted crystals on reduction in uterine size, the diameter of the previously pregnant uterine horn was measured sonographically in 7 control cows with the same parity as the experimental cows. Because no difference in diameter was detected between the groups, we concluded that the implanted crystals did not affect the reduction in uterine size.

In conclusion, the sonometric system tested in our study appears suitable for the objective assessment of reduction in uterine size in cows. A reference method for the assessment of the reduction in uterine length does not exist, and an indirect validation of sonometric measurements using the uterine cross-sectional diameter was used instead. Despite the high level of invasiveness, the method used in the current study did not affect the rate of reduction in uterine size. Accidental detachment of crystals from the myometrium was readily recognized in most cases by the characteristic pattern of the recordings and, after exclusion of erroneous measurements, the data from the detached crystals could largely be used for further analysis. However, it should be remembered that this sonometric system is largely limited to monitoring reduction in uterine length, and that it should therefore ideally be combined with another examination technique, such as B-mode sonography. Sonomicrometry is a promising technique for monitoring the effects of postpartum disease on reduction in uterine length and the effect of therapeutic measures to improve uterine involution in abnormal cows. 


\section{ACKNOWLEDGMENTS}

The authors thank Zoetis (Florham Park, NJ) for funding this study. The authors are also grateful to Christian Schmidt for the use of the cows at the Agrargesellschaft mbH Siedenlangenbeck (Siedenlangenbeck, Germany) dairy farm.

\section{REFERENCES}

Adelson, D. W., and M. Million. 2004. Tracking the moveable feast: Sonomicrometry and gastrointestinal motility. News Physiol. Sci. 19:27-32.

Ahn, A. N., R. J. Monti, and A. A. Biewener. 2003. In vivo and in vitro heterogeneity of segment length changes in the semimembranosus muscle of the toad. J. Physiol. 549:877-888.

Bajcsy, A. C., O. Szenci, A. Doornenbal, G. C. van der Weijden, C. Csorba, L. Kocsis, I. Szucs, S. Ostgard, and M. A. Taverne. 2005. Characteristics of bovine early puerperal uterine contractility recorded under farm conditions. Theriogenology 64:99-111.

Bekana, M., T. Ekman, and H. Kindahl. 1994. Ultrasonography of the bovine postpartum uterus with retained fetal membranes. Zentralbl. Veterinarmed. A 41:653-662.

Biewener, A. A., W. R. Corning, and B. W. Tobalske. 1998. In vivo pectoralis muscle force-length behavior during level flight in pigeons (Columba livia). J. Exp. Biol. 201:3293-3307.

Breeveld-Dwarkasin, V. N., P. C. Struijk, F. Eijskoot, F. K. Lotgering, F. M. van Dissel-Emiliani, G. C. van der Weyden, and M. A. Taverne. 2002. Ultrasonic cervimetry to study the dilatation of the caudal cervix of the cow at parturition. Theriogenology $57: 1989-2002$

Burton, M. J., R. C. Herschler, H. E. Dziuk, M. L. Fahning, and R. Zemjanis. 1987. Effect of fenprostalene on postpartum myometrial activity in dairy cows with normal or delayed placental expulsion. Br. Vet. J. 143:549-554.

Dawson, B., and R. G. Trapp. 2004. Basic and Clinical Biostatistics. McGraw-Hill Professional, New York, NY.

Fonseca, F. A., J. H. Britt, B. T. McDaniel, J. C. Wilk, and A. H. Rakes. 1983. Reproductive traits of Holsteins and Jerseys. Effects of age, milk yield, and clinical abnormalities on involution of cervix and uterus, ovulation, estrous cycles, detection of estrus, conception rate, and days open. J. Dairy Sci. 66:1128-1147.

Fourichon, C., H. Seegers, and X. Malher. 2000. Effect of disease on reproduction in the dairy cow: A meta-analysis. Theriogenology $53: 1729-1759$

Frazer, G. S. 2005. A rational basis for therapy in the sick postpartum cow. Vet. Clin. North Am. Food Anim. Pract. 21:523-568.

Gajewski, Z., R. Thun, R. Faundez, and Z. Boryczko. 1999. Uterine motility in the cow during puerperium. Reprod. Domest. Anim. 34:185-191.

Gier, H. T., and G. B. Marion. 1968. Uterus of cow after parturition: Involutional changes. Am. J. Vet. Res. 29:83-96.

Gillette, D. D., and L. Holm. 1963. Prepartum to postpartum uterine and abdominal contractions in cows. Am. J. Physiol. 204:11151121.

Heppelmann, M., L. Krueger, S. Leidl, and H. Bollwein. 2013. Transrectal Doppler sonography of uterine blood flow during the first two weeks after parturition in cows. J. Vet. Sci. 14:323-327.

Hirsbrunner, G., B. Knutti, H. Burkhardt, U. Kupfer, and A. Steiner. 1999. Effect of two dosages of d-cloprostenol on intrauterine pres- sure and uterine motility during dioestrus in experimental cows. Zentralbl. Veterinarmed. A 46:345-352.

Kamimura, S., T. Ohgi, M. Takahashi, and T. Tsukamoto. 1993. Postpartum resumption of ovarian activity and uterine involution monitored by ultrasonography in Holstein cows. J. Vet. Med. Sci. $55: 643-647$.

Korinek, J., J. Vitek, P. P. Sengupta, A. Romero-Corral, V. K. Krishnamoorthy, E. M. McMahon, B. K. Khandheria, and M. Belohlavek. 2007. Does implantation of sonomicrometry crystals alter regional cardiac muscle function? J. Am. Soc. Echocardiogr. 20:1407-1412.

Krueger, L., J. Koerte, G. Tsousis, K. Herzog, G. Flachowsky, and H. Bollwein. 2009. Transrectal Doppler sonography of uterine blood flow during the first 12 weeks after parturition in healthy dairy cows. Anim. Reprod. Sci. 114:23-31.

Kündig, H., R. Thun, K. Zerobin, and B. Bachmann. 1990. The uterine motility of cattle during late pregnancy, labor and puerperium. I. Spontaneous motility. Schweiz. Arch. Tierheilkd. 132:77-84.

Littell, R. C., J. Pendergast, and R. Natarajan. 2000. Modelling covariance structure in the analysis of repeated measures data. Stat. Med. 19:1793-1819.

Melendez, P., J. McHale, J. Bartolome, L. F. Archbald, and G. A. Donovan. 2004. Uterine involution and fertility of Holstein cows subsequent to early postpartum $\mathrm{PGF}_{2 \alpha}$ treatment for acute puerperal metritis. J. Dairy Sci. 87:3238-3246.

Morrow, D. A., S. J. Roberts, and K. McEntee. 1969. A review of postpartum ovarian activity and involution of the uterus and cervix in cattle. Cornell Vet. 59:134-154.

Morrow, D. A., S. J. Roberts, K. Mcentee, and H. G. Gray. 1966. Postpartum ovarian activity and uterine involution in dairy cattle. J. Am. Vet. Med. Assoc. 149:1596-1609.

Okano, A., and T. Tomizuka. 1987. Ultrasonic observation of postpartum uterine involution in the cow. Theriogenology 27:369-376.

Ouyang, H., and J. D. Chen. 2005. Assessment of gastric volume changes with sonometry compared with barostat. Neurogastroenterol. Motil. 17:447-452.

Ribeiro, E. S., F. S. Lima, L. F. Greco, R. S. Bisinotto, A. P. Monteiro, M. Favoreto, H. Ayres, R. S. Marsola, N. Martinez, W. W. Thatcher, and J. E. Santos. 2013. Prevalence of periparturient diseases and effects on fertility of seasonally calving grazing dairy cows supplemented with concentrates. J. Dairy Sci. 96:5682-5697.

Rodriguez-Martinez, H., D. McKenna, P. G. Weston, H. L. Whitmore, and B. K. Gustafsson. 1987. Uterine motility in the cow during the estrous cycle. I. Spontaneous activity. Theriogenology 27:337-348.

Sheldon, I. M., and H. Dobson. 2004. Postpartum uterine health in cattle. Anim. Reprod. Sci. 82-83:295-306.

Taverne, M. A., V. N. Breeveld-Dwarkasing, F. M. van Dissel-Emiliani, M. M. Bevers, R. de Jong, and G. C. van der Weijden. 2002. Between prepartum luteolysis and onset of expulsion. Domest. Anim. Endocrinol. 23:329-337.

Van Camp, S. D. 1991. Understanding the process of placental separation and uterine involution. Vet. Med. 86:642-646.

van Engelen, E., M. A. Taverne, M. E. Everts, G. C. van der Weijden, A. Doornenbal, and V. N. Breeveld Dwarkasing. 2007. Cervical diameter in relation to uterine and cervical EMG activity in early postpartum dairy cows with retained placentas after $\mathrm{PGF}_{2 \alpha}$ induced calving. Theriogenology 68:213-222.

Watson, E. D. 1985. Ovarian activity and uterine involution in postpartum dairy cows with mild and moderate fatty infiltration of the liver. Br. Vet. J. 141:576-580.

Zerobin, K. 1970. The movement of the uterus in cows during birth and post partum. Schweiz. Arch. Tierheilkd. 112:544-560. 